Promoting Language and Literacy Development for Early Childhood Educators: A Mixed-Methods Study of Coursework and Coaching

\author{
Susan B. Neuman \\ Tanya S. Wright \\ University of Michigan
}

Acknowledgement: This study was funded by the Early Childhood Educator Professional Development Program, Office of Elementary and Secondary Education, U.S. Department of Education

(In Press, Elementary School Journal) 


\section{Promoting Language and Literacy Development for Early Childhood Educators: A Mixed-Methods Study of Coursework and Coaching}

Proximal features of teaching quality, including teachers' instructional practices, and the quality of supports in the environment, play a primary role in fostering children's school readiness skills (Pianta, Mashburn, Downer, Hamre, \& Justice, 2008). Numerous studies (Dickinson \& Caswell, 2007; Wasik, Bond, \& Hindman, 2006), for example, have shown that teachers who engage children in rich language interactions, help them to become sensitive to the sounds and letters in words, and involve them in content-rich, purposeful instruction promote the skills associated with later reading success. Such supportive environments help all children, but especially those from less advantaged circumstances who are less likely to experience stimulating early childhood environments at home or in their neighborhood communities (Neuman, 2009).

Although empirical research underscores the importance of these teaching practices to later development (Landry, Swank, Smith, Assel, \& Gunnewig, 2006), there is limited research on how to promote the development of teachers' knowledge and skills in these critical areas, particularly among those who are in mid-career. This realization has led to a number of funded initiatives (e.g. the U.S. Department of Education Early Childhood Educator Professional Development Program; Early Reading First) to create professional development programs that specifically address the needs of early childhood educators. Recognizing the special challenges of educating the early childhood workforce (Zaslow \& Martinez-Beck, 2006), specifically financial limitations, and turnover rates, an emerging consensus of evidence (Zaslow, 2009) suggests that training and 
ongoing support may be necessary to transfer knowledge and skills into daily literacy practices.

Several recent empirical trials (Koh \& Neuman, 2009; Landry, Anthony, Swank, \& Monseque-Bailey, 2009; Powell, Diamond, \& Burchinal, 2009), in fact, have demonstrated positive changes in early literacy practices as a result of specialized training and supports. Dickinson and Caswell (2007), for example, designed the Language Environment Enrichment program (LEEP), a 45 hour in-service course to help teachers build knowledge about literacy, and to employ best practices in their classrooms. At the same time, they built ongoing supports into training by having on-site supervisors work with teachers throughout the project. Within a six month period, the researchers found moderate to large positive effects on all measures of classroom supports, with the exception of writing, related to literacy development. Similarly, Jackson and her colleagues (Jackson et al., 2006) reported significant improvements in language and literacy practices with subsequent effects on preschoolers' literacy skills resulting from a professional development program that included a 15-week HeadsUp! professional development literacy workshop series and mentoring.

These and other studies (Domitrovich, Gest, Gill, Jones, \& DeRousie, 2009; Landry, Swank, Smith, Assel, \& Gunnewig, 2006) have recognized that effective professional development is specific and targeted, involving many opportunities for practice with feedback in the context of one's own practice. It provides teachers with adequate time to reflect on their own practices, to set goals, and to self-evaluate. It extends beyond time-limited in-service workshops conducted outside of the classroom, by including some kind of outside support or mentorship. In short, high quality 
professional development is a dynamic process that requires teachers to be both reflective and open to new practices with the overriding goal of improving instruction for young children.

It is this type of dynamic support that has attracted policymakers, practitioners and researchers to the potential of coaching and consultation as a form of professional development in recent years. Long used in athletic training programs and leadership programs (Nettles, 1993), the application of coaching to early literacy and early childhood teaching is still relatively new. While there are many forms (e.g. content focused, and student-focused) (Salinger, 2006) and practices, the consensus among applications appears to be that coaching is a form of professional development that involves ongoing classroom modeling, supportive critiques of practice, and specific observations (Joyce \& Showers, 2002; Shanklin, 2006). Similar in many aspects to consultation (Pianta, Mashburn, Downer, Hamre, \& Justice, 2008), coaching involves a collaborative relationship between an expert and a practitioner to develop specific knowledge and skills related to instructional practice.

Although there are promising indications that coaching may be an effective approach for improving teachers' language and literacy practices (Poglinco \& Bach, 2004), there is little empirical support for its use, especially as an independent professional development strategy. That is, to date, coaching has been in combination with more formal training through coursework, or concentrated workshops (Sheridan, Edwards, Marvin, \& Knoche, 2009).

Moreover, little is known about the strategies coaches use in sessions (Powell, Diamond, \& Burchinal, 2009; Powell, Steed, \& Diamond, in press). Although 
observations, demonstrations, and goal-setting appear as often-cited strategies for development, the balance of these activities are seldom elucidated as well as their influences on teaching practices. Not only the strategies, but the intensity, depth, duration of treatment — dosage-- needs to be considered if we are to provide high quality professional development for literacy improvement (Halle, 2008; Ramey \& Ramey, 2008). How much professional development is necessary to achieve changes in practice? How long, and with what frequency and depth? (Halle, 2008). Consequently, these critical issues about coaching need to be addressed empirically to determine its longerterm utility for improving quality practices and positive child outcomes in language and literacy development.

Given the size of the investment in professional development and the dependence of educational reform on providing high quality professional development, the knowledge base of effective practices needs to be strengthened (Zaslow \& MartinezBeck, 2006). In this paper, we report on the results of an effort to better understand the independent contribution of coaching as the sole mechanism for improving teacher practice and child outcomes in early language and literacy development. Specifically, we sought to compare the potential benefits of professional development through coaching or coursework with a control group who received no additional professional development on quality early literacy practices.

The results we report here build on a previous large-scale analysis of professional development for center- and home based providers. Together, the earlier study and the one reported here help to highlight the strengths and potential weaknesses of different forms of professional development for improving teaching practices in early literacy. In 
addition, it provided some initial insights on the issue of dosage and intensity of professional development outside of our ability to directly subject it to experimental manipulation.

\section{$\underline{\text { Results from our First Professional Development Initiative }}$}

Funded through the Early Childhood Educator Professional Development Grant (USDOE), our first project was designed to improve the knowledge and skills of midcareer early childhood educators and to build capacity for those working in child care centers, faith-based centers, family and group day care homes serving the very poorest children in Michigan.

To build a scalable approach to professional development, the Project assembled a collaboration of educational, child care, and public service organizations headed by the University of Michigan including Community Coordinated Child Care Association (4C) Care), three state government agencies (Health, Education and Human Services) and community colleges. Working with regional $4 \mathrm{C}$ offices which maintained databases for all regulated child care providers, the project identified center-based providers who had earned a Child Development Associates (CDA) or less, or an Associates Degree or higher degree out-of-field, and who lived in the attendance areas of these high priority urban areas. These providers became the target population for an intensive professional development program.

Recognizing the paucity of research on the effects of different forms of professional development, we designed a study that enabled us to examine the relationships between alternate forms of professional development and changes in teacher knowledge and teaching practices. Reported in greater detail in Neuman and 
Cunningham (2009), we briefly summarize the findings to serve as context to the present study.

Our sample included providers from 304 center- and home-based child care settings in four of the priority urban centers. Approximately two-thirds of the teachers were Caucasian, the other third, African-American; participants were in their mid-career, with limited formal training in early childhood education and no training in early literacy development. Providers were randomly selected to one of three groups: Professional development coursework at their local community college in early literacy development; Professional development coursework plus weekly coaching for 32 weeks (designed to put in place practices described in coursework), and control, business as usual, with the goal of improving teacher knowledge about early literacy and quality teaching practices in these early care and education settings.

Our study found that professional development plus coaching was related to significant increases and educationally meaningful changes in providers' skills and practices in both centers and home-care settings. Professional development coursework alone did not lead to improvements in either teacher knowledge or practice. In fact, scores on both measures for this group were indistinguishable from controls.

Nevertheless, our design could not disentangle the effects of coaching from coursework. We could not detail whether coaching was the mechanism for improving teacher practice or whether it was the combination of treatments. In addition, coached providers were given more extensive professional development-- as much as 64 hours of additional contact. It might well have been an issue of the differential dosages of treatment. Further, although our study ensured fidelity to the coaching model, we could 
not clearly identify the active ingredients of coaching or its particular influence on practices.

The research reported here was designed to build on these findings. Specifically, our goal was to examine the effects of coaching or coursework compared to a control group on teacher knowledge and teacher practice. We also wished to explore whether the effects of treatment might be influenced by dosage, exploring how a smaller dosage of professional development developed for this study might compare with our previous research. We addressed the following questions in this mixed-methods study:

- Are there differences between the forms of professional development (coursework or coaching) compared to a control group on the improvement of teachers' knowledge of early literacy development?

- Does the form of professional development impact improvements in the quality teaching practices in early language and literacy?

- How might a smaller dosage influence professional development?

- What are the strengths and weaknesses from the participants' point of view of these different forms of professional development?

\section{Method}

\section{$\underline{\text { Participants }}$}

This multi-site study took place in Fall, 2007 through Spring, 2008 in six cities in Michigan: Detroit, Cadillac, Flint, Grand Rapids, Jackson and Lansing. Recruited by the state-wide 4C organization in cooperation with the Department of Human Services' Teacher Education and Compensation Helps program (T.E.A.C.H.), participants received 
scholarships and incentives upon completion of the program. Across the sites, participants included 148 early childhood educators who were housed in 148 community centers or public schools. These teachers were distributed across the sites as follows: Detroit (10\%); Cadillac (9\%), Flint (24\%); Grand Rapids (10\%); Jackson (24\%); and Lansing (24\%). Participating centers/schools all served children and their families from low-income backgrounds. Demographic characteristics of participating early childhood educators are summarized in Table 1.

Insert Table 1 about here

To be eligible for the professional development program, teachers needed to meet the following criteria: 1) They needed to be open to taking a course at their local community college or participating in on-site coaching in early literacy; 2) they had to be employed at least 20 hours per week in a licensed pre-K; and 3) they had to care for children within the ages of three to five; 4) they needed to have an agreement from their sponsoring organization (Center Director; educational director; principal), indicating their willingness to participate in the project.

Participants were randomly assigned to treatment: Group $1(\mathrm{~N}=58)$, professional development 3-credit course in early language and literacy at their local community college and Group $2(\mathrm{~N}=58)$, professional development through coaching; Group 3 $(\mathrm{N}=32)$, the wait-list comparison group had no professional development course or coaching (with the understanding that such opportunities would be available next year). 


\section{$\underline{\text { The Professional Development Intervention }}$}

The professional development intervention constituted a 30-hour program starting in September 2007 in early language and literacy development. Participants randomly assigned to Group 1 received a professional development course held at one of six locations closest in proximity to the child care site. Participants randomly selected for Group 2 received professional development through on-site individualized coaching. Participants in Group 3, the wait-list comparison, received no professional development. Each intervention is described below.

Language and literacy course. Working collaboratively with faculty partners at a multi-site community college, we adapted a three-credit course in early language and literacy to be consistent with research and best practices. Common teaching practices to support early literacy skills such as plentiful verbal interactions, daily shared book reading, repeated readings with multiple genre were emphasized throughout sessions. The course was designed to provide students with the content knowledge and pedagogical skills considered by experts to be essential for quality early language and literacy practice.

Each site used a common course syllabus. All lectures and assignments were taken from the text Early Childhood Experiences in Language Arts $7^{\text {th }}$ edition ((Machado, 2003) and Nurturing Knowledge (Neuman, Roskos, Wright, \& Lenhart, 2007). Specifically, the course focused on developing providers' knowledge in the following areas: oral language comprehension; phonological awareness; letter knowledge and the alphabetic principle; print convention; strategies for working with second language 
learners; literacy assessments; parental role in early language and literacy development; and linkages between literacy and other aspects of the curriculum.

Each class used a lecture format to present the week's topic, followed by simulation and hands-on activities designed to link theory to practice. Instructors used videotape examples frequently in class to augment instruction and to demonstrate examples of quality practices.

Assignments required participants to use course content in their instructional practice and to reflect on their effectiveness. For example, teachers were asked to record themselves engaging with one or two children in a story-book reading situation, and to reflect on children's responses to the story, their interests, and their uses of sophisticated vocabulary. Similarly, another assignment asked teachers to encourage a child or children to write a story "their way" and to examine the products for evidence of developmental writing. These assignments were then used in class discussions to help instructors create linkages between their understanding of child development, early literacy development, and their current practices with children.

The courses were taught by experienced early childhood faculty who also served as coordinators for each of the six community colleges. Instructors covered the topics in weekly three-hour classes over a 10-week period. At each site, classes included participants in the study, as well as other students enrolled in the course (Course instructors were not informed of which students were participating in the study). Class size varied between 18-25 students.

Given that the six sites were widely dispersed across the state, we used several indirect methods to determine fidelity of instructional implementation. First, attendance 
was taken at all sites to ensure that students participated in at least 8 of the 10 sessions. (Given that T.E.A.C.H stipends were dependent on attendance and completion of the course, there was high attendance throughout sessions--overall attrition less than $2 \%$ ). Second, weekly conference calls with instructors were conducted to ensure that the pacing of content and materials was maintained throughout the course. Third, unannounced observations by their supervisor who served as a site manager for the project were conducted in each class, and reported high fidelity to the course syllabus. Fourth, instructors were required to send us products from the same four specified assignments (related to reading, writing, oral language, and play) in each class to indicate that students had participated and completed work in these areas. And fifth, evidence from student grades, reviewed by instructors and site manager, indicated that they had completed the course requirements according to the guidelines on the syllabus.

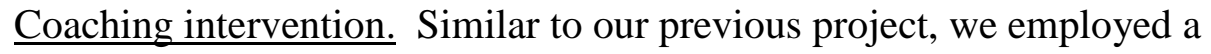
diagnostic/prescriptive model of coaching that focused on helping participants apply research-based strategies to improve child outcomes in language and literacy. Based on a review of best practices (Joyce \& Showers, 1983; International Reading Association, 2004; Koh \& Neuman, 2006), the model was designed to include the following elements: Coaching was on-site, involving teachers in ongoing practice rather than just a temporary infusion of activities. It was designed to facilitate reflection, not to dictate "a right answer.' Further, it emphasized co-teaching through modeling and demonstration--highly interactively strategies-- rather than observation and post-feedback. Coaches were encouraged to establish rapport, and build trust, and to provide useful suggestions rather than evaluate or judge teachers' performance. And in each case, coaches were 
encouraged to help teachers' prioritize, to focus on those activities that might best benefit children's outcomes (Herll \& O'Drobinak, 2004).

To ensure an equal dosage of treatment, sessions were weekly, one-on-one, and on-site, approximately for three hours. Coaches were provided with the course syllabus, and readings, and encouraged to emphasize similar content and skills, though in a manner appropriate to the needs of their participants. For example, coaches would focus on the weekly session on oral language development in the syllabus by guiding, engaging, and planning individual strategies with the teacher to enhance her practices. Therefore, although content plans were highly consistent across settings, coaches were encouraged to tailor the specific techniques in the syllabus to meet teachers' individual needs. Coaching session occurred weekly over a 10-week period.

A number of common procedures were used to ensure fidelity of coaching across sites. Coaches were required to fill out coaching logs (described below) and meet weekly in debriefing sessions with the instructional coordinator at each site. These meetings were designed to discuss the challenges and successes of their weekly efforts, and to determine goals, strategies and action plans for completing next steps. These debriefing sessions gave coaches opportunities to review their notes with others and to share experiences and resources. They also served as an accountability mechanism for us, providing information on any missed or rescheduled sessions, as well as the number of hours they worked. In addition, the project manager made an unannounced visit to coaches throughout the intervention. Detailed observations from these visits provided us with feedback on the quality of the coaching sessions, and on the participants' reactions to professional development. 
Procedures Related to the Implementation of the Professional Development Programs

Project Management: The multi-site project was staffed by a project manager in the field, responsible for supervising the instructors and coaches, and by a project manager in the research office, responsible for all data collection, fidelity to treatment, and research-related scheduling. The two teams held two full-day meetings prior to and during the study to review the project. Following the initial meeting, both teams held biweekly telephone conference calls to review the project status, address critical questions, and provide ongoing feedback from the field.

Instructors at each site were seasoned early childhood specialists, having had more than 10 years of teaching experience at the college level. All had masters' degrees in early childhood, and had taught in early childhood settings prior to moving to higher education. Each instructor assumed two roles: one was to teach the early language and literacy course; and the other was to direct, and facilitate weekly sessions with coaches to ensure an alignment of course content, and their activities in the field.

Coaches were hired locally at each site. Based on scheduling, coaches worked with 1 to 3 providers in 52 different locations. Thirty were Caucasian and two, AfricanAmerican. Approximately half had their BA degrees with an additional credential in early childhood; and half had their Masters' degree. Two-thirds of the coaches had experience in working with adults in the past. Most of the coaches were retired, having previously taught or directed programs or worked as adjunct college level instructors; others were part-time teachers. All, however, had substantial early childhood experience with over half reporting 15 years or more in the classroom. 
Coaches met in a two-day coaching institute to provide an orientation to the project and to review the training model. Specific key research-based practices were discussed, and the general topics and the knowledge base essential for early literacy reviewed. Social etiquette was also emphasized, reminding coaches that they were neither a friend nor a supervisor, but a professional 'mentor' in the setting. Coaches role-played specific scenarios, and brainstormed solutions to common problems. Finally, we described specific procedures to be used throughout the study.

Based on geographic locations, coaches were randomly assigned to participants. Participants were called and informed that they would receive weekly coaching for the semester. Coaching began during the same week as the professional development coursework, and ended after the 10-week semester was completed.

Progress monitoring: To examine the qualities of coaching, we created an online coaching log. It was designed to be a scalable and cost-efficient method to gather information on coaching that would allow for close to "real time" monitoring of sessions. Based on the work of Rowan, Camburn, \& Correnti (2004) the log was designed to be a 15-minute self-reported "diary of activities." Research by Rowan and Correnti (2009) had shown that such self-reported measures could be highly valid and reliable if used frequently and within several days of enactment. Coaches were asked to complete the $\log$ within 48 hours of each coaching session; these logs became instantly accessible to the research team.

The log included 65-items. To monitor fidelity to the program structure, items requested information on the date and duration of sessions, the coaching techniques used by the coach during the session, as well as the coach's key goal for the session. Specific 
sections of the log included questions about the coaches' pedagogical strategies, areas of concentration throughout the session, as well as fidelity to the program syllabus and the language and literacy goals for providers. Aligning items with research-based practices, coaches were asked to tell us whether they worked to "create or improve a dedicated book area" or "involve children in interactive storybook reading." After each item, coaches were asked to check "focus of session," indicating that the activity was their prime focus; "touched on briefly" suggesting more of a teachable moment; or "not addressed." Given that coaches were encouraged to set priorities, we did not expect to see all sections covered 'a lot.' The goal was to help coaches and providers focus their efforts on key objectives. Sections included: general environment, assessment, book reading, writing, teacher-child interactions, oral language and vocabulary development. Within each section, we asked about specific content practices, such as "reading from a variety of genre." Coaches were asked to check the appropriate items that emphasized their activities in their work with the providers at each session.

Coaches were trained on the use of the log as part of a day-long coaching institute. Coaches were expected to complete one session per week with each of their providers. Instructors and coaches also reviewed logs weekly to provide feedback and further discussion. In total, 505 coaching logs were collected over the course of the study.

\section{Measures Used for Program Evaluation}

Prior to the start of the study, we examined teacher knowledge and teacher practice in early language and literacy development using measures from our previous 
study. Specifically, all teachers were assessed in their knowledge of language and early literacy using a specially-developed measure. Observations of teacher practices in language and literacy occurred simultaneously in early September before the professional development intervention. Immediately following the intervention, we conducted posttests and post-observations. After a five-month period, we once again administered the ELLCO (Smith \& Dickinson, 2002) to examine longer-term effects on practice.

Teacher Knowledge Assessment of Early Language and Literacy Development. The teacher knowledge assessment (Neuman \& Cunningham, 2009) is a multiple-choice, true-false 70-item test designed to examine participants' growth in knowledge of early language and literacy. Two forms of the assessment were developed for pre- and posttest purposes, with an average completion time of 45 minutes. Overall reliability was high (Cronbach's alpha =.96). The assessment was placed on SurveyMonkey to facilitate multi-site data collection. Participants were given a gift certificate upon returning the assessment.

Teacher Practice. We used the Early Language and Literacy Classroom Observation (ELLCO) (Smith \& Dickinson, 2002) to measure the instructional and environmental supports for language and literacy in the preschool classrooms. The ELLCO is composed of three interdependent research tools: The Literacy Environment Checklist assesses the visibility of literacy-related materials as books, alphabet, word cards, teacher dictation, alphabet puzzles, and writing implements. The Observational Ratings span activities including reading aloud, writing, assessments, presence or absence of technology which are examined along a rubric of 1 (deficient) to 5 (exemplary). The Literacy Activities Rating Scale summarizes information on the nature and duration of 
literacy activities such as book reading and writing during the observation period. Reliability of the instrument for all three components of the toolkit, as measured by Cronbach's alpha for the entire scale is .90 (Smith \& Dickinson, 2002).

Data collection was conducted by trained graduate students in educational psychology. Research assistants received a full day training workshop on the use of ELLCO which included video and photographic examples to assist raters in making their decisions. All research assistants then received field training on the measure from an expert who had prior experience. During the field training, new observers and experts independently coded ten observations. Cohen's kappa statistic (Cohen, 1960; 1968) was used to calculate inter-rater reliability. The weighted kappa was .65, indicating substantial reliability. After training and certification, research assistants independently observed settings. Average observation time was 1 1/2- 2 hours in length.

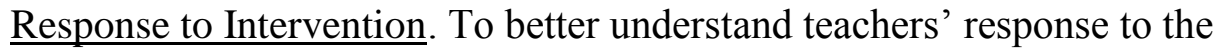
professional development, 54 participants were randomly selected from the coursework and coaching groups and interviewed following the intervention. The interview included 12 open-ended questions designed to assess how the professional development coursework or coaching might affect the participant's classroom practices. Interviews were 45-minutes to 1 hour, tape-recorded, and transcribed verbatim.

\section{Results}

In this section we first address the differential effects of the intervention on teachers' knowledge of early language and literacy development. Second, we examine differences in language and literacy practices across the two professional development 
groups and the control group. These measures reflected our view that professional development should involve a focus on content knowledge expertise in early language and literacy as well as the development of sound instructional practice.

To conduct the quantitative analysis, we used the analysis of covariance (ANCOVA), a general linear model to examine the impact of the intervention. We entered the corresponding pretest score as a covariate on each of our outcome measures for knowledge and practice. We then conducted post-hoc analyses using Tukey HSD to examine the statistically significant differences among the three groups. ${ }^{1}$

Third, following the quantitative analysis, we studied our qualitative evidence to better understand the conditions that might have influenced our results. We used two approaches to analysis. The first was enumeration (LeCompte \& Preissle, 1993), a data analysis technique that uses frequency counts to identify categories of phenomena. It was designed to operationally identify patterns of coaching activity. Reviewing the 505 coaching logs, we examined the coaching strategies and content foci to better describe the pedagogical emphases used most frequently in coaching sessions. We counted how many times each coaches addressed a particular topic, such as "creating a writing center" over the ten sessions. We then grouped items into theoretical clusters according to content foci. For example, a focus on writing included: helping children practice writing their own names; writing stories with children; encouraging invented spellings etc. We tallied items for all coaches, and calculated a mean number of sessions devoted to each content cluster. Together, these data provided a rough estimate of how time was spent during coaching sessions.

\footnotetext{
${ }^{1}$ We did not use HLM since the grouping structure used in the model must be consistent across all individual-level variables (see Raudenbush \& Bryk, 2002, p. 102-111). There were different grouping structures (e.g. the control group in this study who received no professional development) in this study.
} 
Lastly, we reviewed the interviews from the randomly selected participants to attempt to understand how the particular forms of professional development might relate to practice. Here we used typological analysis, a second qualitative strategy (Jacob, 1987). Typological analysis begins with an intensive review of materials - in this case, the transcripts from participants in both interventions. After identifying a number of categories, interviews are then examined for patterned regularities among categories which form the basis for consequential explanations. Because these categories serve descriptive purposes, they are considered to be generative, used for analyzing subjective data. Following this analysis, we provided a brief report to a selected number of participants as a form of "member check" (Miles \& Huberman, (1984) to verify that the analysis captured their perspectives accurately.

Therefore, using a mosaic of methods both quantitative and qualitative, our goal was learn more about the active ingredients of different forms of professional development in relation to changes in early literacy knowledge and practices.

\section{Teacher Knowledge}

Table 2 reports pre- and posttests scores on the Teacher Knowledge Assessment of Early Language and Literacy Development. Standard scores on the pretest, ranging from $0-100$, showed that on average, providers clearly demonstrated prior knowledge of key concepts in early literacy prior to taking the course. There were no significant differences between groups prior to treatment $(\mathrm{F} 2,145)=.001$, n.s. 
Insert Table 2 about here

Following professional development, post-test scores for both groups showed only modest increases. Using pretest scores as covariates, we conducted an analysis of covariance (ANCOVA). Since teacher's education level differed by treatment group, teachers' education was entered into the analysis of covariance along with the pretest score to adjust for prior educational background and prior knowledge. Although the pretest scores were significant, $\mathrm{F}(1,145)=51.03, p<.001$, educational background was not, $\mathrm{F}(1,145)=.03, p=\mathrm{n} . \mathrm{s}$; therefore, only pretest scores were included as the covariate in the analyses of posttest scores. The ANCOVA reported no significant differences between groups on posttest scores, $\mathrm{F}(2,145)=.11$, n.s.

These results indicated that neither treatment condition significantly outperformed the control group on posttest knowledge scores. Further, scores at posttest were essentially equivalent for participants in both treatment groups, indicating that neither condition appeared to improve teacher knowledge of early language and literacy.

\section{Teacher Early Language and Literacy Practices}

Next, we examined the impact of professional development on early literacy practices both immediately after the intervention with a subsequent follow-up five months later.

Insert Table 3 about here 
Table 3 presents descriptive pre- and post- and follow-up test scores on the ELLCO. A one-way analysis of variance indicated no statistically significant differences between groups prior to treatment $(\mathrm{F} 2,145)=.06$, n.s. Using the pretest score as a covariate, we then entered our main predictor variable, treatment, into an analysis of covariance (ANCOVA) adjusting for pretest differences. Our analysis revealed significant differences between groups on the structural characteristics of the environment immediately following the intervention. These differences included quality improvements in the Book area, $\mathrm{F}(2,145)=3.92, p<.05$, the Writing area, $\mathrm{F}(2,145)=$ $10.62, p<.001$, and the Literacy Environment overall $(\mathrm{F} 2,145)=8.97, \mathrm{p}<.001$. Tukey post-hoc analyses indicated statistically significant differences between those who received coaching compared to the course or control group. According to Cohen (1988), an effect size of +.25 or more is considered an educationally meaningful difference. The effect size for quality improvements in the book area using Cohen's $d$, was educationally meaningful for coaching (Group 2) compared to the control group (Group 3) at .36 and stronger still for coaching (Group 2) compared to coursework at .45. The results were substantial for improvements in the writing area (coaching compared to control, 1.02; compared to coursework,.77) There were no significant differences between Group 1, the professional development coursework and the control group.

Follow-up ANCOVA analyses indicated that these improvements were maintained for the coaching group (ES .45 compared to Group 1; ES .57 compared to control) some five months later. In fact, there were slight increases in scores compared to those immediately following the intervention. Together, these results indicated that professional development through coaching significantly improved the structural features 
of the early language and literacy environments in centers. Unlike coaching, no significant improvements appeared to result from the professional development course which remained statistically equivalent to the control group.

The ANCOVA analyses, however, reported no differences between groups in the process characteristics of quality: Interactional Environment, $\mathrm{F}(2,145)=2.20$, n.s., Support for Learning, $\mathrm{F}(2,145)=.86$, n.s., and Teaching Strategies, $\mathrm{F}(2,145)=.48$, n.s. Although there were small increases in quality improvements in these areas for professional development in both groups, neither was sufficiently powerful to make substantive improvements in these areas. These results indicated that neither course nor coaching significantly enhanced the psychological supports and teaching strategies in these centers.

\section{Content and Pedagogical Focus in Coaching}

We analyzed the coaching logs to better understand why coaching appeared to improve the structural characteristics of quality literacy practices but not the process characteristics. Given that process characteristics, such as teacher interaction and engagement are regarded as critical features of early literacy development (Dickinson \& Caswell, 2007), we sought to learn more about the active ingredients of coaching activity. As shown in Figure 1, coaches spent considerable time setting goals with teachers, promoting reflection, observing classroom practice and providing feedback. These activities indicated overall fidelity to our coaching model and were all supported in training.

Insert Figure 1 about here 
Nevertheless, fewer sessions were spent on teaching strategies. According to selfreports coaches did not spend many sessions on planning with teachers, co-teaching and modeling new instructional strategies. Coaches appeared to guide rather than directly interact with teachers during lessons.

To study this pattern more specifically, we examined coaches' activities in writing and reading, the structural areas of quality which had shown significant improvements and maintenance over time. For both areas, we created two theoretical clusters, one focusing on the environment features, and the other on the instructional strategies. The writing environment, for example, included: creating or improving a dedicated writing area, ensuring that there was a variety of paper available for children; and ensuring that there were writing/drawing tools available for children to use. Writing instructional strategies, on the other hand, included: helping children practice writing their own names; writing stories with children; and encouraging children's early invented spelling.

Conducting a t-test, we found significant differences between these two factors $(t=1.98, p<.05)$. On average, coaches were inclined to focus on improving the environment rather than on helping teachers focus on the teaching strategies known to support children's developmental writing (slightly more than $2 \frac{1}{2} 2$ sessions devoted to

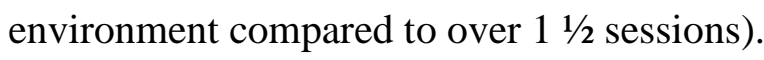

A similar pattern was reported for reading. Here, we clustered items associated with the reading environment that included: creating or improving a dedicated book area; ensuring that there are an appropriate number of books in the space, making a variety of 
books available to children. Reading instructional strategies included: creating daily times for reading aloud to children; coordinating shared book reading with ongoing themes or projects; using discussion and questioning during shared book reading. A t-test revealed marginal differences, $(\mathrm{t}=1.86, \mathrm{p}<.06)$. Coaches spent more time on the environmental characteristics ( 2 sessions) in centers than on the teaching strategies (slightly over 1 1/2 sessions) associated with literacy improvements.

In this respect, these results appeared to buttress and partially explain the quantitative results. The structural features of centers improved as a result of coaching because coaches spent time working with teachers on these aspects of quality improvements. Less attention was spent on teaching strategies associated with these features, however, resulting in only modest improvements.

Nevertheless, these results stood in contrast to our previous study, which had shown improvements in both structural and process characteristics, resulting from 32 weeks coaching. Consequently, we examined whether the emphasis of environment over instruction might be related to dosage: In other words, might coaches simply not have sufficient time to effectively work with teachers on improving their instruction?

To conduct this analysis, we focused on shared book reading as an example, looking at the percent of times coaches addressed environmental and instructional characteristics across sessions.

Insert Figure 2 about here

Results in Figure 2 indicated that coaches emphasized improvements in the book 
area in early sessions. With relative efficiency, coaches first appeared to address weaknesses in the literacy environment early on in their work with teachers. However, they needed more time to improve instruction. Sessions devoted to shared book reading instructional strategies did not taper off even at session ten, indicating their need to improve their teaching practices, or the process characteristics associated with reading.

\section{$\underline{\text { Response to Professional Development Intervention }}$}

In our final analysis, we sought to learn more about the strengths and weaknesses of these different forms of professional development from the participants' point of view. Specifically, what did or did not appear to influence practice? Here, our typological analysis (Jacob, 1987) was designed to reveal patterns, detailed below, that might further explain our quantitative findings.

Professional Development Coursework. Participants in Group 1 had high praise for the course. They enjoyed their instructors and equally, across sites, gave positive reviews. Nevertheless, it was clear that many had difficulties. Participants struggled with the literacy demands of the course, the translation from theory to practice and the translation from what they were learning in their class to their individual context.

Literacy Demands: Many of the teachers in the study were either returning to college after many years, or new to college instruction. Interview comments suggested that they found the pacing of the course, the requirements of reading and the information itself very demanding. One participant said it this way:

"In that book we went through the names of people that did certain things in child care. And that just didn't sink in my head. I couldn't comprehend it. I can't even 
remember what they did and their names and stuff."

Some found the textbook difficult to read, and had trouble keeping up the assignments. They were expected to read two chapters from the textbook, a chapter from the applied book each week and, at the same time, to juggle additional assignments. One teacher commented: "It was a big-sized book [textbook] but it was too short of time we had to do it." Further, many did not see the relevance of the readings to their practice. For example, one participant indicated: "There was a ton of reading that I felt, you know, wasn't necessary. I found that projects were more beneficial than reading."

Too theoretical: It was not only the literacy demands of the textbook they questioned. It was the "what" they were reading and learning as well. Much of the material in the course, they believed, appeared to focus more on 'why we do certain literacy practices," rather than 'what and how to do them.' For example, one teacher commented that they learned about why it was a good idea to put a word and a picture label together, and why children should be allowed to handle books. But when asked what she would like to learn more about, she turned to examples of the concrete materials they made in the classroom. One reported,

"The instructor gave us time to ask questions and she'd tell us the why of everything. And I'd say, oh, well, yeah, that explains why I need to do this. But when asked what was most helpful about the course, she replied:

"I would say how we took stories and we made flannel-boards and different props to go along with it. What really stood out for me was learning about felt stories and making props for stories."

Teachers seemed to enjoy the lively discussions and the sharing of ideas in the 
course. At the same time, they reported that it was the making of concrete materials-flannel board stories, puppets, homemade books-- that seemed to be most relevant and most closely tied to their practice. While instructors encouraged teachers to use these materials in their classroom instruction and to report back on their use, neither the activity enactment nor its quality of implementation were monitored other than through class assignments and discussion.

Consequently, the course presented several challenges to these nontraditional students. The literacy demands were high, and concepts were relatively abstract, requiring a strong translation to classroom practice. Although teachers believed they learned about many new activities, they were not consistently translated into literacy practices that they felt they could use.

Coaching practices. Participants in Group 2, coaching, also praised their professional development training. All had high marks for their coach. But unlike participants in the coursework group, it was the practicality of the training that appeared to be referred to in their comments. Especially effective, it was on-site, and contextspecific training that held them accountable.

Individualized and context-specific: Teachers appeared to appreciate the individualized attention, and special focus on making improvements in their environment. Many contrasted their experience with previous professional development. As one put it:

"You know you got a conference and you're bombarded with so many things its hard to remember...its hard to take it all in. And you go through your notes and say, "Oh my gosh I don't remember what that was about."

In contrast, coaches helped teachers try out strategies immediately in their own 
environment and get instant feedback for their efforts. One teacher said:

"You get the one-on-one, hands on attention. You know you go to a seminar or something and you go and learn and you come back. But you may not be doing it the way that it would be best. You know, you may think that you learned it right when you were there. And then you come home and you think, "Oh I forgot how to do this.' Where she [coach] is here to work with you on things."

New resources: Many times, without specific directions, coaches would bring and demonstrate new resources to teachers. For example, coaches would show them websites that provided useful lesson plans and materials. They made journals for the children so that the teacher could better implement writing in their daily curriculum. They brought catalogues to support literacy-related play. In some contexts, coaches literally flooded their sites with new materials and resources, as one teacher commented:

"She would always bring some sort of resource, whether it was a book, or an article, things like that. She would go over it, bit by bit, answer any questions that I had. And she would give me some advice or recommendations."

In this respect, it was the practice-based nature of coaching — directly tied to the context in which these teachers worked with children — that appeared to be its most distinctive feature. Coaches talked about ideas and the "why's" of literacy not in a vacuum but in the context of practice.

Informal Accountability: Even though coaches had no supervisory role, there was inherent accountability in the coaching cycle. With coaches visiting weekly, teachers often wanted to act responsive and to make the changes discussed the previous week. As one teacher articulated, "If you have a one-to-one relationship with someone, you don't 
want to disappoint them. So whether or not you like it, you do the work." In addition, the weekly goal setting appeared to help teachers focus on particular practices. By establishing priorities, the changes made each week could be more attainable. One teacher put it this way:

"I think it's worthwhile to have somebody come in. You can go and learn something. That doesn't mean that you're going to come back and implement it. Where if there's somebody coaching you on, and you're making the goal that next week, okay, we're going to A and she comes back and A is not done, you're going to feel pretty crummy that we talked... yes I told you that I would do A and I didn't do A, you know. Where if I took the classes and I said to myself, yeah I'm going to do this next week, well, I'll wait until the following week and then it'll be put off for a month or whatever."

These and other comments revealed that coaching appeared to support individualized, context-specific practices along with an informal accountability cycle that provided real-time feedback to teachers. As a model of professional development, it seemed to support a practice-based approach (Neuman \& Cunningham, 2009), one that provided a more immediate translation of ideas to classroom practice than the traditional workshop or course. It also provided an informal monitoring devise, designed not to evaluate but to improve quality practices.

\section{Discussion}

This study is among the first randomized controlled trials to examine different 
forms of professional development in early childhood and their impact on quality language and literacy practices. Results indicated that coaching was a more effective professional development form than coursework for improving the structural characteristics in classrooms. Differences among groups on these structural features were educationally meaningful, with effect sizes moderate to large in these areas of change. These improvements were maintained, and to some degree, enhanced five months after the intervention was over. Given that these structural variables have been strongly linked to quality practices and child outcomes in previous research (Dickinson \& Caswell, 2007; Smith \& Dickinson, 2002), it suggests that coaching can be an effective form of professional development. It also shows that coaching can be scaled up in typical early childhood education settings.

This study builds on previous research in professional development (Koh \& Neuman, 2009; Neuman \& Cunningham, 2009). In the previous study, professional development coursework and coaching was shown to significantly improve quality practices compared to coursework alone. By disentangling the two forms of professional development and by providing an equal dosage of treatment, we were able to examine each form independently. Our results provide further confirmation for the benefits of coaching. Changes in the structural quality of the classrooms resulted for teachers who were coached versus for those who received coursework only or no professional development program. In fact, consistent with our previous findings, we found that differences between the professional development course and the control group were negligible.

Findings from this research, however, showed that changes in the quality of 
language and literacy practices in classrooms were more modest than our previous research. Less marked changes were found on teaching supports and strategies in the current study. The lack of improvement may indicate that it is harder to make the kinds of changes in teaching practices captured by the ELLCO than it is to change structural supports for literacy. To receive higher scores on these sections of the ELLCO, for example, teachers needed to be able to intervene in writing activities, and to ask openended questions in shared book reading activities--more complicated pedagogical strategies than merely changing the provision and access to resources.

Therefore, these differences in our findings might reflect the dosage of treatment (Halle, 2008). In the previous study, teachers received a year-long, 77 hour professional development program (45 hours of course plus 32 hours of coaching). In this study, they received 30 hours of professional development. It could be that the training goals in this training were too ambitious to be addressed in such a brief time period as 30 hours.

There is some evidence to suggest that dosage was an issue. While self-reported, coaching logs indicated that coaches worked first on the structural characteristics of change - the environment. As sessions continued, they increasingly addressed the process characteristics of change. Further research should explore the important role that dosage and duration might play in enhancing these process characteristics.

Our experience working with teachers in high-need priority urban areas also confirmed a finding from our previous research: professional development coursework alone does not appear to produce changes in quality practices in classrooms. Given the enormous number of resources being devoted to professional development as a mechanism for quality improvements (Zaslow \& Martinez-Beck, 2006), these results 
have clear implications. If we want to affect changes in classrooms and quality services for children, professional development programs will need to employ some kind of application to practice. Based on our interviews, it was clear that the on-site, individual and personal nature of coaching created an accountability mechanism that was tailored to helping the teacher enact better instruction. It gave teachers' regular feedback promote learning in key skill domains.

Our studies showed no effects on knowledge gains resulting from traditional coursework. It could be argued that our assessment, based on model similar to Praxis, was too insensitive to the more subtle gains in knowledge in the course. Or it could be that there might be sleeper effects later on. However, we suspect it might be related to the 'decontextualized' nature of the professional development. As our interviews indicated, traditional coursework often provide valuable lessons for 'why' to do a particular strategy. Yet it was clear that these nontraditional students had difficulty with the assignments, the literacy demands of the texts, the concepts and names, and were more inclined to focus on "how to do it" through concrete hands-on learning techniques. These results certainly do not negate the utility of coursework for professionalizing the early childhood workforce (Whitebook, 2003); however they do suggest that we may need to adapt courses to better address the needs of providers, many of whom are nontraditional learners. Doescher and Beudert (in press) reported increases in retention in their community college program as a result of mentors who provided additional help and translational activities to teachers throughout their studies.

Finally, this study provided some insights on the active ingredients of coaching. Our coaching model was designed to be diagnostic and prescriptive, highlighting careful 
planning, reflection, and goal-driven strategies to improve language and literacy instruction. While coaches followed the overall model with high fidelity, the coaching $\log$ revealed that they were disinclined to demonstrate, model, co-plan and co-teach lessons. Demonstration of effective practices and exemplary models however, may be a more powerful technique than these other more ethereal processes (International Reading Association, 2004; Sandefur, Warren, \& Gamble, in press), especially for nontraditional learners.

\section{$\underline{\text { Limitations and Future Directions }}$}

It is important to note several important limitations in the study. For one, although the design of the study was a randomized controlled trial, all teachers volunteered to participate in the study and showed interest in professional development. Those randomly selected to receive coursework or coaching were willing to commit the time and energy to participate in a professional development effort. Therefore, we cannot extrapolate our findings to the larger population of early childhood educators who may not be so inclined to seek professional development. Second, our findings relate to teachers in early childhood settings in poor communities, and therefore, should not be generalized to average or middle- to upper-income areas. Third, in retrospect it would have ideal to include a professional development course and coaching group. Addressing both dosage and format, however, would have been difficult. Subsequent research is needed to identify the level of dosage needed to improve outcomes. It could be, for example, that dosage levels might vary for teachers of different competency levels. Fourth, our measures of content knowledge and early language and literacy practices may not have been sensitive enough to pick up the more subtle areas of changes in knowledge 
and practice. Further research is needed to develop highly reliable and valid assessments (National Research Council, 2001) which may tap incremental gains over time. Fifth, single level regression analyses may underestimate standard errors and therefore, overestimate statistical significance. And finally, although the language and literacy practices associated with these measures have been known to be strongly predictive of language and literacy development (Dickinson, Miller, \& Anastasopoulos, 2001; Neuman, 1999), we cannot determine whether these changes in practices result in improved children's language and literacy skills. As we have reported here, the most potent instructional features (e.g. teacher-child interaction) appeared to be most resistant to change. We need to be cautious, therefore, when extrapolating from observed changes in the environment to likely changes in children's performance. An investigation is currently underway to examine these relationships.

In sum, coaching appears to improve a number of quality practices in language and development for early childhood educators. It reaches teachers "where they are," demonstrating that quantitative changes in language and literacy development in the short-term are possible when professional development is targeted, individualized, and applicable to its audience. 


\section{References}

Cohen, J. (1960). A coefficient for agreement for nominal scales. Educational and psychological measurement, 20, 37-46.

Cohen, J. (1988). Statistical power analysis for the behavioral sciences (2nd ed.). Hillsdale, NJ: Erlbaum.

Dickinson, D., \& Caswell, L. (2007). Building support for language and early literacy in preschool classrooms through in-service professional development: Effects of the Literacy Environment Enrichment Program (LEEP). Early Childhood Research Quarterly, 22, 243-260.

Dickinson, D., Miller, C. M., \& Anastasopoulos, L. (2001). The impact of an in-service intervention with Head Start teachers and supervisors on children's language, literacy, and social development. Paper presented at the Society for Research in Child Development, Minneapolis, MN.

Doescher, S., \& Beudert, J. (in press). Professional development in the community college setting. In S. B. Neuman \& M. Kamil (Eds.), Professional Development for Early Childhood Educators: Principles and Strategies for Improving Practice. Baltimore, MD: Brookes.

Domitrovich, C., Gest, S., Gill, S., Jones, D., \& DeRousie, R. (2009). Individual factors associated with professional development training outcomes of the Head Start REDI program. Early Education and Development, 20, 402-430. 
Halle, T. (2008, October 17). Dosage of professional development: What have we learned. Paper presented at the Conference on Early Childhood Professional Development, Ann Arbor, MI.

Herll, S., \& O'Drobinak, B. (2004). Role of a coach: Dream keeper, supporter, friend. Journal of Staff Development, 25(2), 42-46.

International Reading Association. (2004). The role and qualifications of the reading coach in the United States; A position statement of the International Reading Association. Newark, DE: International Reading Association.

Jackson, B., Larzelere, R., St. Clair, L., Corr, M., Fichter, C., \& Egertson, H. (2006). The impact of HeadsUp! Reading on early childhood educators' literacy practices and preschool children's literacy skills. Early Childhood Research Quarterly, 21, 213226.

Jacob, E. (1987). Traditions in qualitative research: A review. Review of Educational Research, 57, 1-50.

Joyce, B., \& Showers, B. (1983). Power in staff development through research on training. Alexandra, VA: Association for Supervision and Curriculum Development.

Joyce, B., \& Showers, B. (2002). Student achievement through staff development (3rd ed.). Alexandra, VA: Association for Supervision and Curriculum Development.

Koh, S., \& Neuman, S. B. (2006). Exemplary elements of coaching. Ann Arbor: Univeristy of Michigan. 
Koh, S., \& Neuman, S. B. (2009). The impact of professional development on family child care: A practice-based approach. Early Education and Development, 20(3), $537-562$.

Landry, S., Anthony, J., Swank, P., \& Monseque-Bailey, P. (2009). Effectiveness of comprehensive professional development for teachers of at-risk preschoolers. Journal of Educational Psychology, 101(2), 448-465.

Landry, S., Swank, P., Smith, K., Assel, M., \& Gunnewig, S. (2006). Enhancing early literacy skills for preschool children: Bringing a professional development model to scale. Journal of Learning Disabilities, 39, 306-324.

LeCompte, M. \& Preissle, J. (1993). Ethnography and qualitative design in educational research. San Diego: Academic Press.

Machado, J. (2003). Early childhood experiences in the language arts (7th ed.). New York: Delmar.

Miles, \& Huberman. (1984). Qualitative data analysis. Beverly Hills, CA: Sage.

National Research Council (Ed.). (2001). Knowing what students know: The science and design of educational assessment. Washington, D.C.: National Academy Press.

Nettles, S. M. (1993). Coaching in community settings. Equity and Choice, 9, 35-37.

Neuman, S. B. (1999). Books make a difference: A study of access to literacy. Reading Research Quarterly, 34, 286-312.

Neuman, S. B. (2009). Changing the odds for children at risk: Seven essential principles of educational programs that break the cycle of poverty. New York: Teachers College Press. 
Neuman, S. B., \& Cunningham, L. (2009). The impact of professional development and coaching on early language and literacy practices. American Educational Research Journal, 46(2), 532-566.

Neuman, S. B., Roskos, K., Wright, T., \& Lenhart, L. (2007). Nurturing Knowledge: Linking literacy to math, science, social studies and much more. New York: Scholastic.

Pianta, R., Mashburn, A., Downer, J., Hamre, B., \& Justice, L. (2008). Effects of webmediated professional development resources on teacher-child interactions in prekindergarten classrooms. Early Childhood Research Quarterly, 23, 431-451.

Poglinco, S., \& Bach, S. (2004). The heart of the matter: Coaching as a vehicle for professional development. Phi Delta Kappan, 85(5), 398-402.

Powell, D., Diamond, K., \& Burchinal, M. (2009). Effects of a professional development intervetnion on teaching processes and child language and literacy outcomes. Paper presented at the Society for Research on Child Development, Denver, CO.

Powell, D., Steed, E., \& Diamond, K. (in press). Dimensions of literacy coaching with Head Start teachers. Topics in Early Childhood Special Education.

Ramey, S., \& Ramey, C. (2008, October 17). Dosage of Professional Development: Why, When, and Where We Think This Matters and What the Evidence Shows. Paper presented at the Conference on Early Childhood Professional Development, Ann Arbor, MI.

Raudenbush, S. \& Bryk, A. (2002). Hierarchical linear models: Applications and data analysis methods (2 ${ }^{\text {nd }}$ Ed.). Thousand Oaks, CA: Sage. 
Rowan, B., Camburn, E., \& Correnti, R. (2004). Using teacher logs to measure the enacted curriculum in large-scale surveys: A study of literacy teaching in 3rd grade classrooms. Elementary School Journal, 105, 75-102.

Rowan, B., \& Correnti, R. (2009). Studying reading instruction with teacher logs: Lessons from the Study of Instructional Improvement. Educational Researcher, $28,120-131$.

Salinger, T. (2006, April). Coaching in the professional development study. Paper presented at the American Educational Research Association, San Francisco, CA.

Sandefur, S. J., Warren, A., \& Gamble, A. (in press). Coaching: It's not just for little league any more. In S. B. Neuman \& M. Kamil (Eds.), Professional development for early childhood educators: Principles and strategies for improving practice. Baltimore, MD: Brookes.

Shanklin, N. (2006). What are the characteristics of effective literacy coaching? Denver, CO: Literacy Coaching Clearinghouse.

Sheridan, S., Edwards, C., Marvin, C., \& Knoche, L. (2009). Professional development in early childhood programs: Process issues and research needs. Early Education and Development, 20(3), 377-401.

Smith, M., \& Dickinson, D. (2002). Early language \& literacy classroom observation. Baltimore, MD: Brookes.

Wasik, B., Bond, M. A., \& Hindman, A. (2006). The effect of a language and literacy intervention on Head Start children and teachers. Journal of Educational Psychology, 98, 63-74. 
Whitebook, M. (2003). Early education quality: Higher teacher qualifications for better learning environments: A review of the literature. Berkeley, CA: Institute of Industrial Relations.

Zaslow, M. (2009). Strengthening the conceptualization of early childhood professional development initiatives and evaluations. Early Education and Development, 20(3), 527-536.

Zaslow, M., \& Martinez-Beck, I. (Eds.). (2006). Critical issues in early childhood professional development. Baltimore, MD: Brookes. 
TABLE 1

Demographic Characteristics of Teacher Sample by Treatment Group $(N=148)$

\begin{tabular}{|c|c|c|c|}
\hline & $\begin{array}{r}\text { Group 1 } \\
\text { Course (\%) } \\
(\mathrm{N}=58)\end{array}$ & $\begin{array}{r}\text { Group 2 } \\
\text { Coaching (\%) } \\
(\mathrm{N}=58)\end{array}$ & $\begin{array}{r}\text { Group 3 } \\
\text { Control (\%) } \\
(\mathrm{n}=32)\end{array}$ \\
\hline \multicolumn{4}{|l|}{ Race } \\
\hline Asian & $2.3 \%$ & $3.8 \%$ & $0.0 \%$ \\
\hline Black & $9.3 \%$ & $15.4 \%$ & $12.0 \%$ \\
\hline Hispanic & $0.0 \%$ & $1.9 \%$ & $0.0 \%$ \\
\hline White & $83.7 \%$ & $78.8 \%$ & $88.0 \%$ \\
\hline Other & $4.7 \%$ & $0.0 \%$ & $0.0 \%$ \\
\hline \multicolumn{4}{|l|}{ Level of Education } \\
\hline High School Degree or Less & $11.6 \%$ & $15.4 \%$ & $34.0 \%$ \\
\hline Some Coursework & $20.9 \%$ & $17.3 \%$ & $12.0 \%$ \\
\hline $\mathrm{CDA}$ & $30.2 \%$ & $15.4 \%$ & $0.0 \%$ \\
\hline 2-year college or higher* & $37.2 \%$ & $41.9 \%$ & $54.0 \%$ \\
\hline \multicolumn{4}{|l|}{ Years of Work Experience } \\
\hline $0-5$ years & $27.9 \%$ & $26.9 \%$ & $38.0 \%$ \\
\hline $6-20$ years & $62.8 \%$ & $57.7 \%$ & $50.0 \%$ \\
\hline More than 20 years & $9.3 \%$ & $15.4 \%$ & $12.0 \%$ \\
\hline \multicolumn{4}{|l|}{ Job Title } \\
\hline Lead Teacher & $69.8 \%$ & $80.8 \%$ & $80.4 \%$ \\
\hline Assistant/Aide & $30.2 \%$ & $19.2 \%$ & $19.6 \%$ \\
\hline \multicolumn{4}{|l|}{ Setting } \\
\hline Center & $79.1 \%$ & $63.5 \%$ & $58.8 \%$ \\
\hline Family & $20.9 \%$ & $36.5 \%$ & $41.2 \%$ \\
\hline Age (years) & 40.8 & 38.9 & 36.1 \\
\hline
\end{tabular}

Chi-square significance * $\mathrm{p}<.01$ between control and treatments groups 
Table 2. Descriptive Statistics on Teacher Knowledge Assessment of Early Language and Literacy:

Pre- and Posttest Scores by Treatment Group

Group

$\underline{\text { Pretest }}$

$\underline{\text { Posttest }}$

Group 1: PD Course

$59.87 \quad(7.70)$

$63.36(7.51)$

Group 2: PD Coaching

$58.79 \quad(7.98)$

$61.36(7.51)$

Group 3: Control

$60.40 \quad(9.20)$

$61.03(9.61)$ 
Table 3: Means and Standard Deviations on the Early Language and Literacy Classroom Observation

\begin{tabular}{|c|c|c|c|c|c|c|c|c|c|c|c|c|c|c|c|c|c|c|}
\hline \multirow[t]{3}{*}{ Measures } & \multicolumn{6}{|c|}{ Pre-test } & \multicolumn{6}{|c|}{ Post-test } & \multicolumn{6}{|c|}{ Follow-up } \\
\hline & \multicolumn{2}{|c|}{ Course } & \multicolumn{2}{|c|}{ Coaching } & \multicolumn{2}{|c|}{ Control } & \multicolumn{2}{|c|}{ Course } & \multicolumn{2}{|c|}{ Coaching } & \multicolumn{2}{|c|}{ Control } & \multicolumn{2}{|c|}{ Course } & \multicolumn{2}{|c|}{ Coaching } & \multicolumn{2}{|c|}{ Control } \\
\hline & $\mathrm{M}$ & SD & $\mathrm{M}$ & SD & $\mathrm{M}$ & SD & $\mathrm{M}$ & SD & $\mathrm{M}$ & SD & $M$ & SD & $\mathrm{M}$ & SD & $\mathrm{M}$ & SD & $\mathrm{M}$ & SD \\
\hline Books & 9.19 & 3.06 & 8.97 & 3.40 & 8.89 & 3.68 & $\overline{10.26_{a}}$ & 3.59 & $\overline{11.87_{\mathrm{b}}}$ & 3.64 & $\overline{10.56_{a}}$ & 3.71 & 11.09 & 3.43 & 12.59 & 3.17 & 10.46 & 4.19 \\
\hline $\begin{array}{l}\text { Writing } \\
\text { Materials }\end{array}$ & 8.31 & 2.70 & 8.38 & 3.63 & 6.46 & 3.98 & $9.61_{\mathrm{a}}$ & 3.27 & $12.16_{\mathrm{b}}$ & 3.39 & $8.58_{a}$ & 3.61 & $10.09_{a}$ & 3.14 & $12.59_{b}$ & 3.74 & $9.28_{a}$ & 3.97 \\
\hline $\begin{array}{l}\text { Physical } \\
\text { Environment }\end{array}$ & 9.41 & 2.00 & 10.58 & 2.12 & 9.77 & 2.72 & 10.24 & 2.20 & 10.67 & 1.90 & 10.11 & 2.77 & 9.85 & 2.50 & 10.55 & 2.89 & 9.98 & 2.63 \\
\hline $\begin{array}{l}\text { Support } \\
\text { for Learning }\end{array}$ & 10.39 & 2.42 & 11.15 & 2.33 & 10.67 & 2.25 & 11.44 & 1.92 & 11.20 & 1.53 & 10.67 & 2.45 & 11.24 & 1.93 & 11.54 & 2.82 & 10.94 & 2.37 \\
\hline $\begin{array}{l}\text { Teaching } \\
\text { Strategies }\end{array}$ & 21.92 & 5.85 & 23.36 & 5.46 & 22.54 & 6.41 & 25.79 & 5.11 & 27.34 & 5.05 & 25.33 & 7.28 & 26.81 & 5.79 & 28.30 & 5.46 & 25.75 & 7.53 \\
\hline
\end{tabular}

Note. Differences between post-test and follow-up groups measured by ANCOVA controlling for pretest scores. Post-test and follow-up means with the same subscript (a,a) are not significantly different at $\mathrm{p}<.05$ in a Tukey comparison. Post-test means with different subscripts (a,b) are significantly different from one another. 
Figures

Figure 1. Content and Pedagogical Focus of Coaching

Figure 2: Focus of Coaching Strategies Over Sessions in Reading Activity

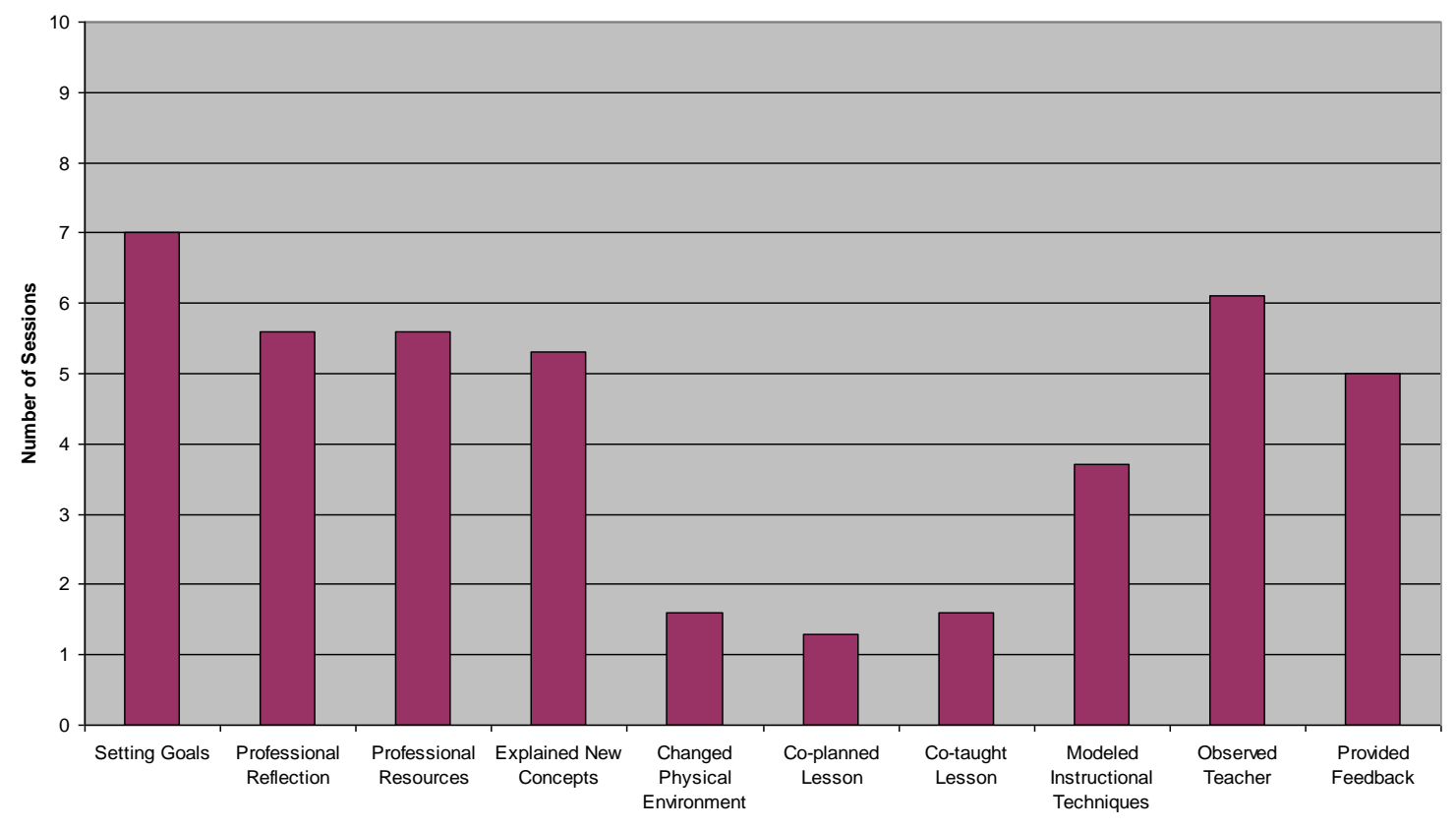




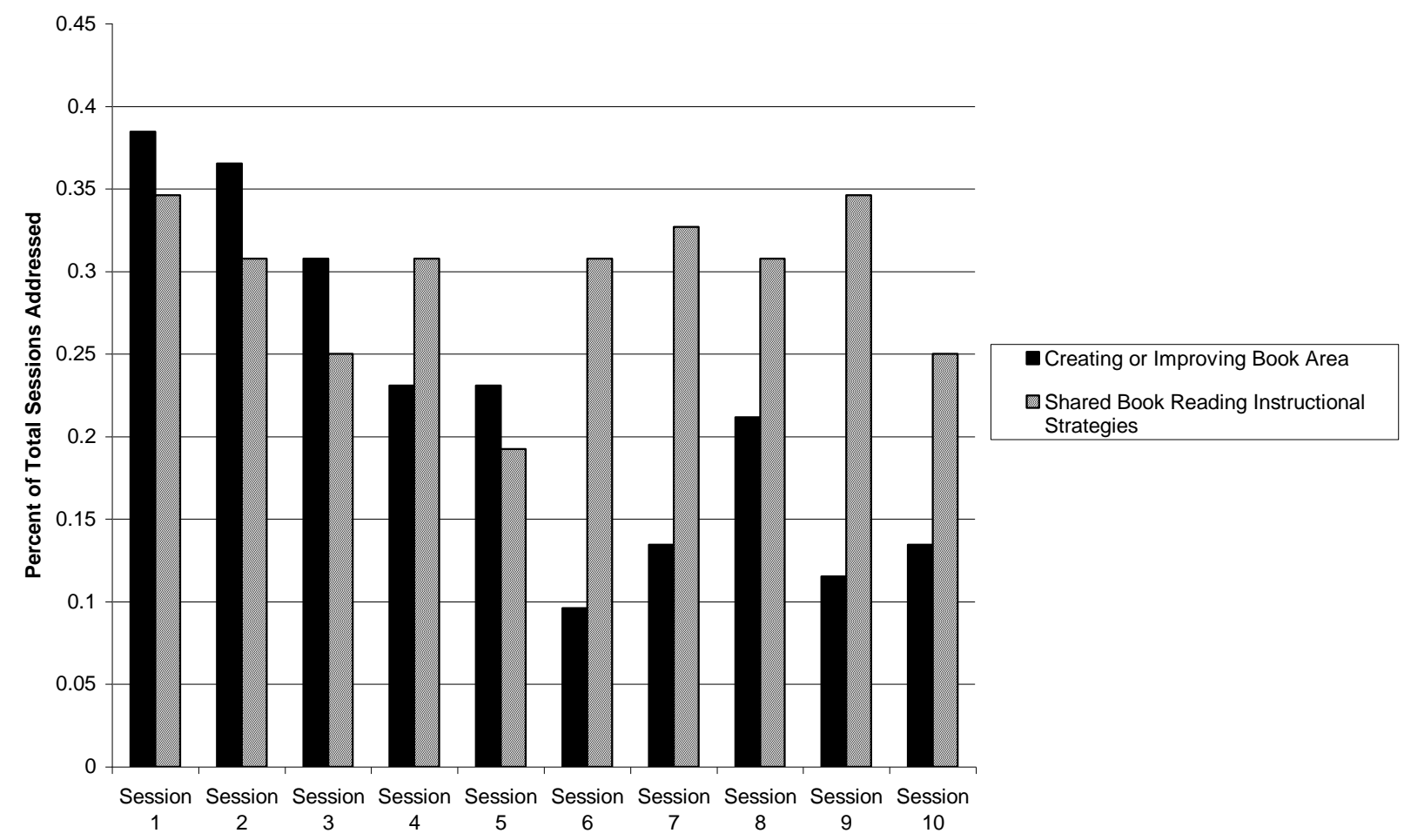


